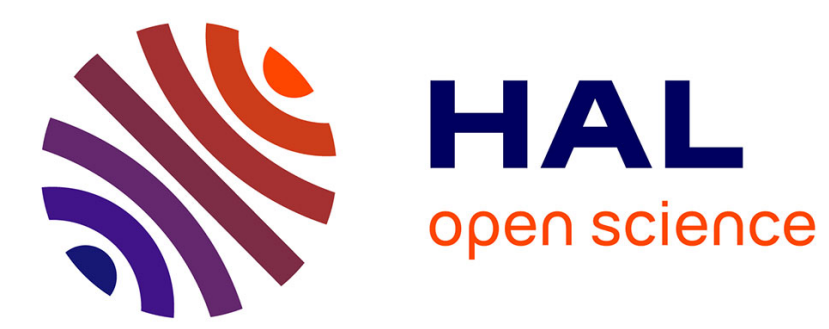

\title{
FIELD ION MICROSCOPY AND ATOM PROBE MICROANALYSIS OF Nb3 Sn WIRES
}

\author{
J.H. Rose, M. Goringe, G. Smith, A. Moore
}

\section{To cite this version:}

J.H. Rose, M. Goringe, G. Smith, A. Moore. FIELD ION MICROSCOPY AND ATOM PROBE MICROANALYSIS OF Nb3 Sn WIRES. Journal de Physique Colloques, 1986, 47 (C2), pp.C2-281-

C2-285. 10.1051/jphyscol:1986242 . jpa-00225676

\section{HAL Id: jpa-00225676 https://hal.science/jpa-00225676}

Submitted on 1 Jan 1986

HAL is a multi-disciplinary open access archive for the deposit and dissemination of scientific research documents, whether they are published or not. The documents may come from teaching and research institutions in France or abroad, or from public or private research centers.
L'archive ouverte pluridisciplinaire HAL, est destinée au dépôt et à la diffusion de documents scientifiques de niveau recherche, publiés ou non, émanant des établissements d'enseignement et de recherche français ou étrangers, des laboratoires publics ou privés. 


\title{
FIELD ION MICROSCOPY AND ATOM PROBE MICROANALYSIS OF $\mathrm{Nb}_{3}$ Sn WIRES
}

\author{
J.D. ROSE, M.J. GORINGE, G.D.W. SMITH and A.J.W. MOORE* \\ Department of Metallurgy and Science of Materials, University of \\ Oxford, Parks Road, GB-Oxford OX1 3PH, Great Britain
}

\begin{abstract}
Nb}_{3} \mathrm{Sn}$ compound superconductor wires have been imaged in the field ion microscope for the first time. Comparison of the observed images with computer-simulated patterns indicates that tin atoms image more brightly than niobium in the ordered structure. Atom probe microanalysis of a grain boundary region showed enrichment in both tin and copper, the latter element being present as an impurity from the "Bronze Process" route used in fabrication. The results are important for understanding both the method of flux pinning and also the mechanism of crystal growth of the material.
\end{abstract}

\section{1 - INTRODUCTION}

$\mathrm{Nb}_{3} \mathrm{Sn}$ composite wires are used extensively in superconducting applications. Fabrication is by a method called the "Bronze Process". This involves the insertion of niobium rods into holes drilled in a bronze block. This composite is then swaged and $d r a w n$, rebundled and further reduced to a final filament diameter of 2 to $5 \mu \mathrm{m}$, the final wire having an overall diameter of about lmm and containing around 6000 individual filaments. This is then formed into its final shape and partially reacted, at $700^{\circ} \mathrm{C}$ for 2 to 3 days, to produce $\mathrm{Nb}_{3} \mathrm{Sn}$ by solid state diffusion.

Recent work by Suenaga et aI. [1] and Tafto et al. [2] has indicated that the grain boundary regions of $\mathrm{Nb}_{3} \mathrm{Sn}$ wires contain amounts of copper significantly above that in the grain interior. The level of tin is also suggested to be higher in the region of the boundaries. Both these results, if confirmed, would have implications for the mechanism of flux pinning, and also for the mechanism of growth of the material. This paper reports a first investigation of $\mathrm{Nb}_{3} \mathrm{Sn}_{\mathrm{n}}$ in the FIM and subsequently in the time of flight atom probe with the objective of clarifying the composition at and near grain boundaries.

\section{2 - EXPERIMENTAL PROCEDURE}

In the production of $\mathrm{Nb}_{3} \mathrm{Sn}$ for its usual applications, the wire is not fully reacted, so as to leave a central core of niobium for strength and stabilisation. For this investigation, however, fully reacted wire was required otherwise only the central core of niobium would have imaged. To achieve full reaction, times of around 28 days at $700^{\circ} \mathrm{C}$ were required. The production of tips by standard FIM preparation techniques [3] proved to be impossible for these composite wires. The technique developed was to mount a lcm length of wire in a nickel tube, and to dissolve away some of the matrix using dilute nitric acid. Then a $90 \% / 10 \% \mathrm{HNO} / \mathrm{HF}$ chemical polish was used, in conjunction with a micropolishing technique, so that only one of the filaments was left standing out from the rest. The very fine diameter of the wires meant that the end form of the protruding filament was difficult to resolve optically, so TEM was used to assess the quality of the tips. Polishing of these ultra fine wires was very difficult, and only a limited proportion of specimens imaged. However, the specimens that imaged successfully began to appear at around $1-3 \mathrm{kV}$. The polishing conditions were such that regions

* Permanent address : 1, story street, Parkvil1e, Victoria 3052 , Australia 
further back down the tip were thinned, often causing premature fracturing, although the specimens would usually still image again at a higher voltage.

The new Oxford atom probe $[4,5]$ (VG Scientific FIM100) was used for the atom probe work. This was because of its superior mass resolution (FWHM 1/2000), compared to the older instrument. The greater resolution was needed so that the niobium peak at $\mathrm{m} / \mathrm{n}=31.0$ did not obscure low concentrations of copper (if present) at $\mathrm{m} / \mathrm{n}=31.5$.

\section{3- FIELD ION MICROSCOPY AND COMPUTER SIMULATION OF IMAGES}

Field ion micrographs were recorded with neon imaging gas at a pressure of about $10^{-5}$ torr, $50 \mathrm{~K}$ tip temperature and at a voltage of about $13 \mathrm{kV}$. A typical image is shown in fig.la.

The texture of $\mathrm{Nb}_{3} \mathrm{Sn}$ wires produced by the "Bronze Process" is known to be strongly $\langle 110\rangle$ [6], so the central pole on the images was provisionally identified as ( 110 ). The images show a regularity of rings and also signs of alternately bright and darker rings, both of which are indications of an ordered phase. Striking features of the images are the parallel rows of atoms lying transverse to the zone lines which radiate away from the central pole.

The structure of $\mathrm{Nb}_{3} \mathrm{Sn}$ is classified as being of the $\mathrm{Cr}_{3} \mathrm{Si}$ type. Interpretation of FIM images from such a complex structure is not straightforward, and computer simulations were required to help in the indexing. Simulations were carried out on a Sirius computer using a shell model [7]. Patterns were generated with only tin atoms imaging, fig.2, or with both species imaging, fig.3. (In each case only a quadrant of the simulated image is shown, with the (100) pole located at the bottom left, and (101) and (011) planes at the top left and bottom right respectively). The best match with the FIM micrographs was obtained for both species imaging, but with the tin atoms brighter than the niobium atoms, fig.4. The simulations show that the most prominent rows of tin atoms lie between the $\{110\}$ and (211\} poles so the indexing of $\mathrm{fig} . \mathrm{lb}$ is done in accordance with this assumption.

\section{4 - MICROANALYSIS RESULTS}

The atom probe analysis of the material was done at $50 \mathrm{~K}$ and $3.10^{-11}$ torr with a pulse fraction of $20 \%$. Analysis of the bulk material gave at most 1 copper ion in $1000, \mathrm{fig} .5$, the overall stoichiometry corresponding to $78.4 \%$ niobium $( \pm 3.1 \%)$, and $21.6 \%$ tin $( \pm 1.6 \%)$. Some hydrogen and oxygen ions were also recorded, but it is believed that these were artifacts of the technique rather than being genuine features of the specimen composition. Only one grain boundary region was found and analysed, fig.6. The composition it gave was $7 \%$ copper ( $\pm 2 \%$ ), $65 \%$ niobium ( $\pm 6 \%$ ) and $28 \%$ tin $( \pm 4 \%$ ) (all results are to one standard deviation). In the matrix close to the boundary, the copper level decreased to zero leaving $81 \%$ niobium ( $\pm 6 \%$ ) and $19 \%$ tin $( \pm 3 \%)$. The anomalously low value of $t$ in concentration that is obtained from the matrix is probably due to the different evaporation potentials of $\mathrm{Nb}$ and Sn: This suggests that the pulse fraction of $20 \%$ is still not high enough to prevent the D.C. standing voltage from removing some tin atoms in the intervals between the high voltage pulses. The relative differences in tin content between the matrix and the boundary are probably still signiflcant, however.

\section{5 - DISCUSSION AND CONCLUSIONS}

The previous work carried out on grain boundaries in this material was by Auger spectroscopy and ALCHEMT (atom location by channelling enhanced microanalysis), and Indicated approximately $25 \%$ and $1.2 \%$ copper respectively, preferentially at the grain boundaries. Bulk analysis [8] has shown that there 1 s usually about $0.5 \%$ copper in the $\mathrm{Nb}_{3} \mathrm{Sn}$. If it is assumed that a grain boundary has a width of $2 \mathrm{~nm}$ and the $\mathrm{Nb}_{3} \mathrm{Sn}$ has an average grain size of about 100nm, then if all the copper is preferentially in the boundary about $6 \%$ atomic concentration should be found in this region. This compares very well with the results found from the present investigation. The work by Suenaga and Jansen [1] also indicates a 5\% higher concentration of $t$ in in the grain boundary region which also compares well with the results found in this investigation. 
Grain boundaries have recently been recognised as effective flux pinning sites [8]. Copper segregation to boundaries can have two effects on this pinning. Firstiy the copper can Zener pin the boundaries during reaction to help maintain a small grain size. Secondly by creating a local chemical inhomogeneity, it can increase the effectiveness of the boundary as a flux pinner (as also could a locally higher concentration of tin). Controlled use of such phenomena may prove to be of value in the further development of superconducting materials.

\section{Acknowledgements}

The authors thank the SERC for provision of funds, Dr.J.A.Lee of AERE Harwe11, U.K. for suppling the composite wires, and other members of the oxford FIM group for their assistance and advice during this project.

\section{References}

[1] Suenaga M. and Jansen W., Appl.Phys.Lett. 43 (1983), 15.

[2] Tafto J., Suenaga M. and Welch D.0., J.Appl.Phys. 55 (1984), 4330.

[3] Brenner S.S. and Miller M.K., J.of Metals, March 1983, p55.

[4] Cerezo A., Smith G.D.W. and Waugh A.R., J.de Physique, 45 (1984), C9-315.

[5] Cerezo A., Godfrey T.J., Moore A.J.W. and Smith G.D.W., J.de Physique, 45 (1984), C9-329.

[6] Togano K. and Tachikawa K., J.AppI.Phys. 50 (1979), 345.

[7] Moore A.J.W., in "Field Ion Microscopy" eds J.J.Hren and S.Ranganathan, Plenum Press, New York (1968) p69.

[8] Suenaga M., "Metallurgy of Continuous Multifilamentary A15 Superconductors", in Superconductor Materials Science, eds. S.Foner and B.B.Schwartz, Plenum Press, New York (1980), p201.

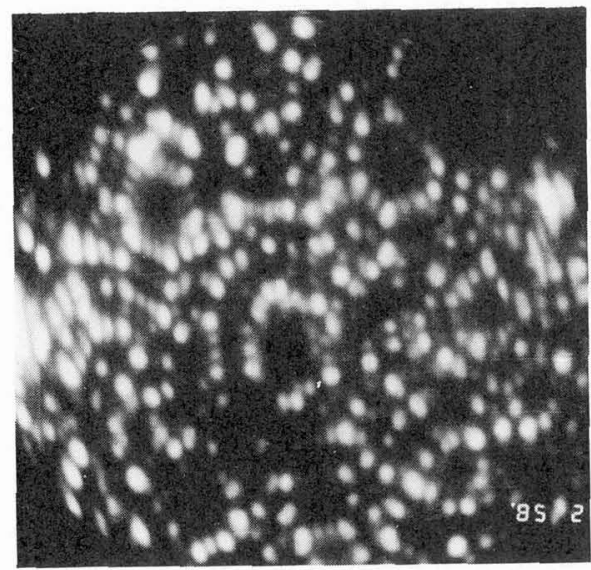

(a)

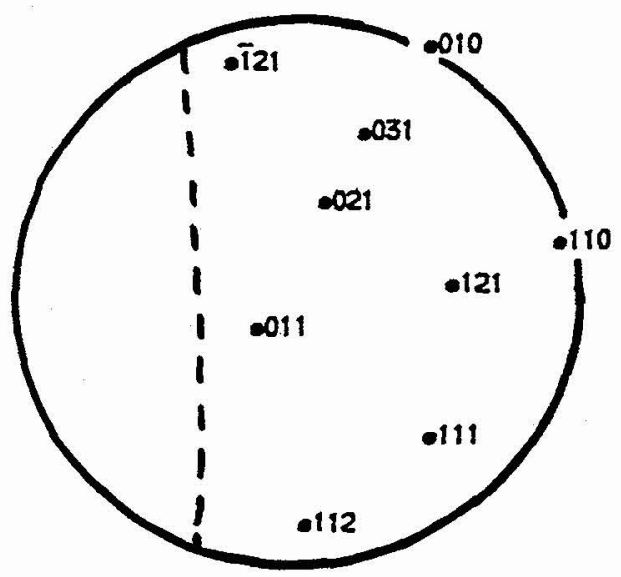

(b)

Fig.1 (a) Neon field ion micrograph of a $\mathrm{Nb}_{3} \mathrm{Sn}$ specimen containing a grain boundary $(50 \mathrm{~K}, 13 \mathrm{kV})$.

(b) Crystallographic indexing of (a), showing location of grain boundary. 


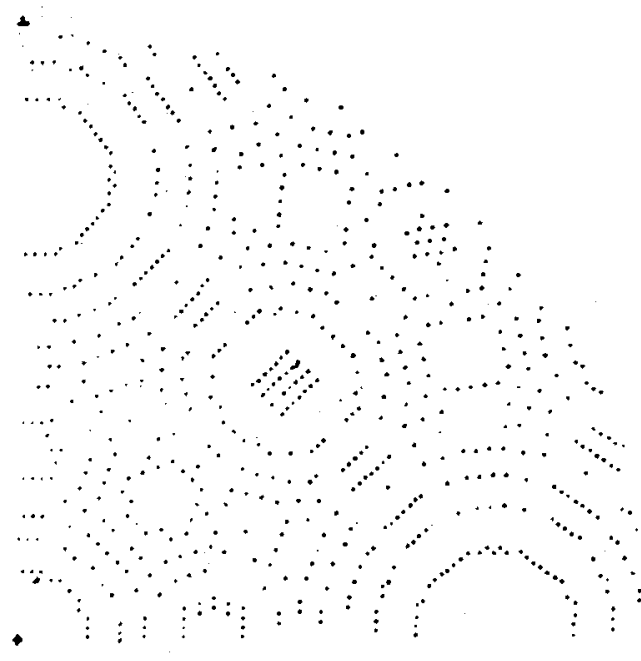

Fig. 2 Computer simulation of $\mathrm{Nb}_{3} \mathrm{Sn}$ FIM image with only the tin atoms appearing.

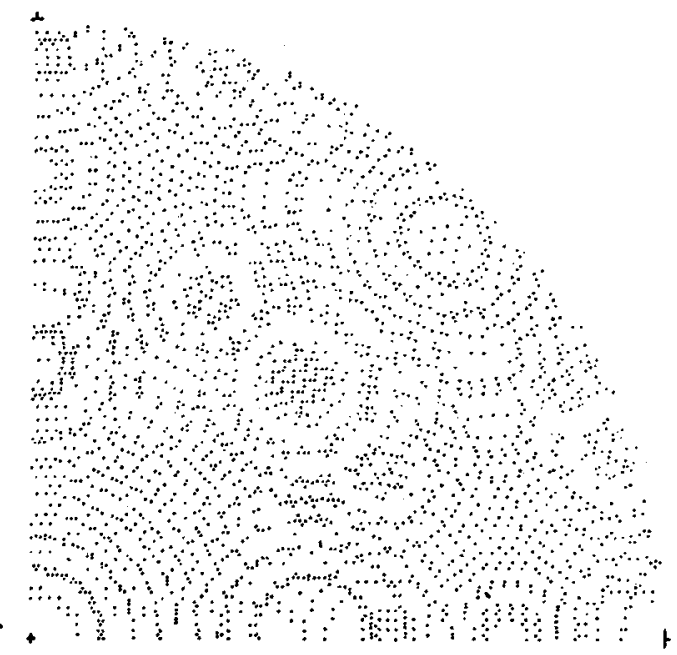

Fig. 3 Computer simulation of $\mathrm{Nb}_{3} \mathrm{Sn}$ FIM image with both tin and niobium atoms appearing equally bright.

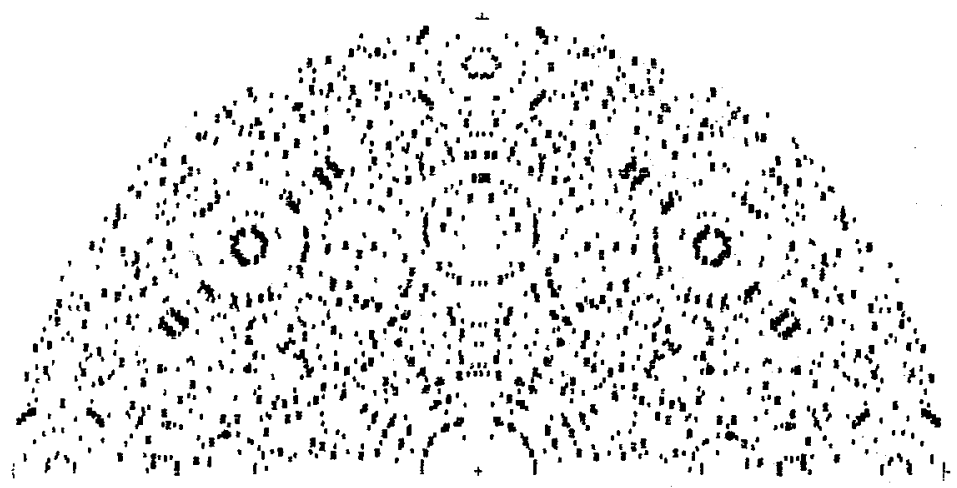

Fig. 4 Computer simulation of $\mathrm{Nb}_{3} \mathrm{Sn}$ FIM image in which the tin atoms appear brighter than the niobium atoms. 


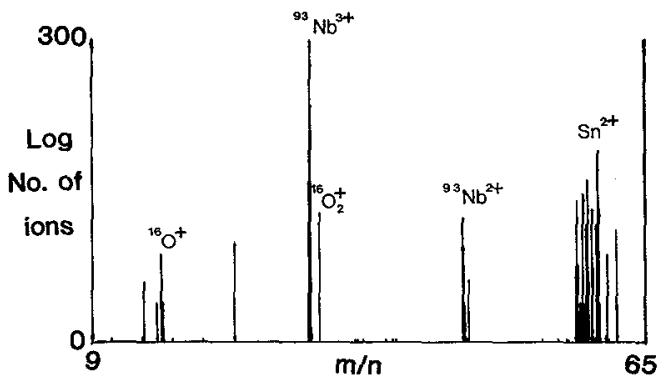

Fig. 5 Atom probe mass spectrum of matrix region. (1000 ions).

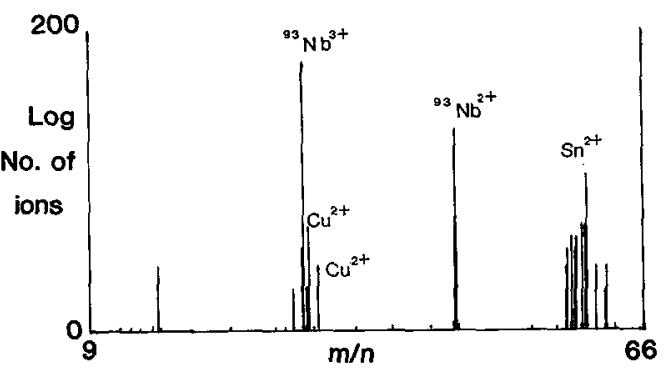

Fig. 6a Atom probe mass spectrum of grain boundary region. (280 lons).

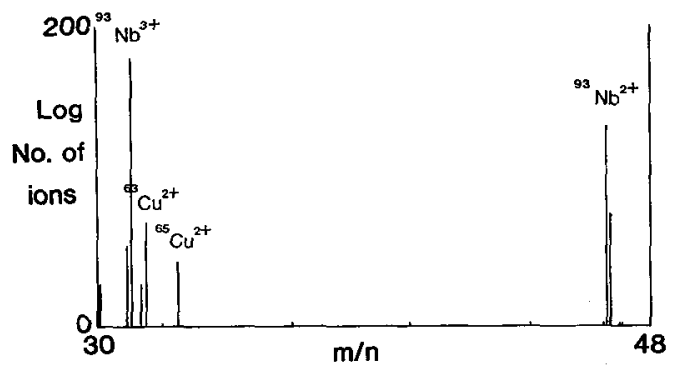

Fig. 6b Enlargement of fig.6a, showing resolution of copper isotopes. 